\title{
The relationship between dyspnea and pulmonary functions in pregnancy, what about the perinatal outcome?
}

\begin{abstract}
Pregnancy is a physiological entity that requires heavy mechanical adaptation and dyspnea is one of the frequent symptoms seen during pregnancy. There are many studies about pulmonary functions during pregnancy. But the effect of pulmonary functions on perinatal outcome is rarely reported. We want to impress especially perinatal outcomes.
\end{abstract}

Methods: Seventy one primipar and normal pregnant women were examined in 8th, 20th and 34th gestational weeks, spirometry, diffusion capacity and muscle strength measurements were done followed by Borg dyspnea scale application. Uterine height and dyspnea score were measured accordingly. Type of delivery, the weight mother gained during pregnancy, birth weight of the baby, any malformation if present and the Activity, Pulse, Grimace: Appearance, Respiration (APGAR) score were recorded. The relationship of between dyspnea scores and these parameters was investigated.

Results: There was no difference in pulmonary functions according to trimesters but uterine dimensions and dyspnea scores were significantly higher in the last trimester. In dyspnea group some spirometric parameters were significantly low. This group also had significantly high incidence of delivery with ceseraen section.

Conclusion: Since respiratory functions are affected during pregnancy which accordingly determines the type of delivery, it's necessary to pay special attention to pulmonary functions during this period.

Keywords: pregnancy, spirometry, muscle strength, diffusion capacity, perinatal outcome
Volume I Issue 2 - 2014

\author{
Gulfidan Cakmak,' Ugur Ates, ${ }^{2}$ Ahmet \\ Cetin, ${ }^{2}$ Mustafa Yenigun, ${ }^{3}$ Tuba Selcuk ${ }^{4}$ \\ 'Department of Pulmonary Medicine, Haseki Education and \\ Research Hospital,Turkey \\ ${ }^{2}$ Department of Obstetric and Gynecology, Haseki Education \\ and Research Hospital,Turkey \\ ${ }^{3}$ Department of Internal Medicine, Education and Research \\ Hospital,Turkey \\ ${ }^{4}$ Department of Radiology, Haseki Education and Research \\ Hospital,Turkey
}

\begin{abstract}
Correspondence: Tuba Selcuk, Department of Radiology, Gelisim University, Department of Medical Sciences, Haseki Education and Research Hospital, Adnan Adivar Street, Fatih, Istanbul, Turkey, Tel 90-532-7843477, Fax 90-2 I2-422067I, Emaildrtubas@gmail.com
\end{abstract}

Received: September 05, 2014 | Published: September 17, 2014

\begin{abstract}
Abbreviations: APGAR, activity pulse grimace appearance respiration; PImax, maximal inspiratory pressure; PEmax, maximal expiratory pressure; DLCO, diffusion capacity; $\beta$-HCG, bbeta human chorionic gonadotropin; BMI, body mass index; FVC, forced vital capacity; $\mathrm{FEV}_{1}$, forced expiratory flow at one second; $\mathrm{FEF}_{25-75}$, forced expiratory flow 25-75; RV, residual volume; TLC, total lung capacity; DLCO/VA, diffusion capacity/alveolar volume; ATS, american torasic sociaty; ERS, european respiratory sociaty; TPC, total pulmonary capacity; SEC, second; MIN, minute; VC, vital capacity; IC, inspiratory capacity; ERV, expiratory reserve volume; RV, residual volume; FRC, functional residual capacity; VT, tidal volume
\end{abstract}

\section{Introduction}

Pregnancy is a physiologic state of health requiring adaptation to serious hormonal and mechanical demands. Some physiologic changes are seen in spirometric parameters and muscle strength. Dyspnea is one of the symptoms quite frequently described by the pregnant women. During pregnancy intra thoracic and intra abdominal pressure changes occur while airway resistance and pulmonary resistance are effected. Abdominal distention affects respiration mechanics. Because of the decrease in the downward movement of the diaphragm, the negative pressure becomes less negative and this leads to a decrease in resting lung volumes..$^{1-7}$ Therefore these symptoms are part of an adaptation mechanism.

Many studies have been reported concerning pulmonary functions in pregnancy. However the related studies found are relatively old dated and the effect on perinatal outcomes is not discussed. It is obvious that in parallel with the rapid development of technology, new and advanced devices are in use which may provide comprehensive knowledge for further evaluation of respiratory functions. PImax and PEmax measurements are useful and noninvasive methods in showing the muscle strength changes ${ }^{8,9}$ and DLCO measurement is as well in determining the gase exchange..$^{10-12}$

The present study aims to understand what happens to pulmonary functions during different stages of pregnancy and to provide additional knowledge on relationship between dyspnea and the effect on perinatal outcome in the light of recent literature.

\section{Materials and methods}

In this prospective study, seventy-one healthy primigravida singleton pregnant women attending to the antenatal outpatient clinic of Istanbul Haseki Training and Research Hospital between January and August 2007 were studied. The pregnancies were confirmed by determining high serum levels of B-HCG. The women who volunteered to participate in the study were consulted to the chest disease specialists and they all undergone physical, biochemical and ultrasonography evaluation. Respiratory function test was applied to the ones who had normal examination results. Nonsmoking volunteering and healthy primigravidas with no previous history of cardiovascular or respiratory disease and who were currently healthy 
regarding physical, biochemical and ultrasonography evaluation were recruited for the protocol. Women with smoking history, spinal and/ or thoracic deformities, pulmonary or neuromuscular pathologies and unable to understand or accomplish the procedure were excluded. The gestational weeks were determined according to Naegeale Formula and the patients were followed up starting at the $8^{\text {th }}$ gestational week through delivery.

In the $8^{\text {th }}, 20^{\text {th }}$ and $34^{\text {th }}$ gestational weeks, the pregnant women underwent routine physical, laboratory and ultrasonographic examinations. Spirometry, diffusion capacity and muscle strength measurements were done as well as Borg dyspnea scale (Borg) application..$^{13}$ Uterine height and dyspnea scores were also measured. Type of the delivery was decided by the gynecologist according to the patient's clinical status. The patients who preferred caesarean section on their own were excluded. The study was completed with fifty two patients. Type of delivery, the maternal weight gained during pregnancy, birth weight, presence of any malformation and the APGAR score were recorded. And finally the relation of all these parameters with dyspnea was investigated.

\section{Spirometric measurements}

In spirometry; $\left.\mathrm{FVC}, \mathrm{FVC} \%, \mathrm{FEV}_{1}, \mathrm{FEV}_{1} \%, \mathrm{FEV}_{1} / \mathrm{FVC}\right), \mathrm{FEF}_{25-75}$, $\mathrm{FEF}_{25-75} \%, \mathrm{RV}, \mathrm{RV} \%$, TLC, TLC $\%$ parameters, in diffusion capacity measurement; DLCO, DLCO \%, Pulmonary CO, DLCO/VA, DLCO/ VA\% parameters, in muscle strength measurements; PImax, PImax \%, PEmax, PEmax\% parameters were assessed.

Spirometric analysis was performed with Jaeger Master Scobe (version 4.5). All respiratory parameters including FVC, FVC FEV $\mathrm{FEV}_{1} \%, \mathrm{FEV}_{1} / \mathrm{FVC}, \mathrm{FEF}_{25-75}, \mathrm{FEF}_{25-75} \%$ were assessed. Spirometric volumes were expressed as $\mathrm{mL}$. We measured lung volumes by a computerized system (SensorMedics Vmax 229; Sensor Medics Corporation, Yorba Linda, CA, USA), following the standardized procedures.

\section{Diffusion capacity}

DLCO and DLCO/VA were measured using standardized singlebreath method and were expressed as mean of two consecutive measurements and DLCO values were expressed as $\mathrm{mL} / \mathrm{mmHg} /$ $\min$. The lung diffusion capacity of the patients were measured using Sensor Medics Vmax 229 and spirometer. DLCO and DLCO/VA were measured using single breath method. The assessment of predictive values for DLCO and other spirometric parameters were predicted on the guidelines of American Thoracic Society. ${ }^{14}$

\section{PImax and PEmax}

The test was performed while the women were seated on a chair at supine position with a nasal clip on in order to prevent nasal inhale and exhale. For PEmax measurement the women were instructed to inhale and exhale for more than one or two times at the tidal volume level and then they were told to inhale to maximum capacity and then to exhale deeply into the pressure transducer for 2-3seconds. PImax was obtained based on the residual volume while the pregnants oriented to exhale and then inhale deeply into the pressure transducer. Then women inhaled to maximum capacity and then exhaled deeply into the transducer for 2-3seconds. Both measurements were repeated three times and the best result which the woman had the best compliance was recorded. Pimax and Pemax were measured with Zan GPI 3.00 Cardiopulmonary Function device performing Respiratory Muscle Function Analysis.

\section{Dyspnea}

The women were questioned for dyspnea at rest, while excersizing or at doing daily activities. The data was then recorded according to the Borg modified dyspnea perception scale where 0 indicates no difficulty and 10, maximum difficulty. Patients with scores 0 or 1 were included to "without dyspnea" and scores 2 and more were included to "with dyspnea" group.

\section{Uterus height}

Fundal uterine height was measured at supine position using a nonelastic metric tape between two index points beginning from the mother's pubic bone (symphysis pubis) to the top of the uterus. Bladder was kept empty and uterus was at relaxing condition while measuring. ${ }^{9}$

\section{Statistical analysis}

All data were recorded at the Statistical Package for the Social Sciences (SPSS) 17 programme. The change in pulmonary functions, dyspnea score and uterine height were assessed according to trimesters and compared with birth records. The correlation between dyspnea and the parameters; age, respiratory parameters, birth weight, maternal weight and fundus height were evaluated with Mann Whitney U Test. Dyspnea and type of delivery were compared with Chi-Square Test. The relationship between pulmonary functional parameters according to the trimesters and the parameters; fundus height, pregnancy weight and birth weight were evaluated with Spearman Correlation Test. P values of $<0.05$ were accepted as significant.

Institutional Approval of the Ethics and Research Committee was taken and the pregnant women who agreed to participate signed an Informed and Independent Consent Form.

\section{Results}

The mean age of the pregnant women was $26,69 \pm 5,09$ years The mean FVC and the standard deviation in the first trimester were $475,00 \pm 564,82 \mathrm{ml}, \mathrm{FEV}_{1}$ was $2902.31 \pm 433.35 \mathrm{ml}, \mathrm{FEV}_{1} / \mathrm{FVC}$ was $83.65 \pm 4.99$ and $\mathrm{FEF}_{25-75}$ was $3064.23 \pm 625.49 \mathrm{ml}$. The values in the last trimester were as follows; FVC, $3458.08 \pm 368.52 \mathrm{ml}$, $\mathrm{FEV}_{1}, \quad 2861.15 \pm 300.15 \mathrm{ml}, \mathrm{FEV}_{1} / \mathrm{FVC}, \quad 82.88 \pm 3.98$ and $\mathrm{FEF}_{25}$ $75,77.54 \pm 16.02 \mathrm{ml}$. While the DLCO value in the first trimester was $22.85 \pm 3.62 \mathrm{~mL} / \mathrm{mmHg} / \mathrm{min}$, the last trimester value was $22.55 \pm 3.90 \mathrm{~mL} / \mathrm{mmHg} / \mathrm{min}$. The RV value in the first trimester was $1261.15 \pm 293.22 \mathrm{ml}$ and its value in the last trimester was $1203.46 \pm 233.75 \mathrm{ml}$. The first trimester and last trimester values of TLC were $4516.92 \pm 756.08 \mathrm{ml}$ and $4472.31 \pm 498.32 \mathrm{ml}$ respectively. When compared, there was a no significant decline at the first and last trimester values $(\mathrm{p}>0.05)$. This decline was more obvious in the group with dyspnea. The PEmax value in the first trimester was $104.49 \pm 23.38 \mathrm{ml}$, while it was $98.74 \pm 16.52 \mathrm{ml}$ in the last trimester. Similarly the PImax value in the first and last trimesters were $78.34 \pm 20.91 \mathrm{ml}$ and $71.18 \pm 18.09 \mathrm{ml}$ respectively. A decrease in these values was detected as pregnancy progressed but this wasn't also statistically significant $(\mathrm{p}>0.05)$ (Table 1$)$.

When compared, the pulmonary functions in the 'dyspnea' group showed a marked decrease in the last trimester (Table 2).

The degree of dyspnea and the fundal uterine height of the pregnants in the last trimester were higher then the values recorded in the first trimester. P values were 0.017 and 0.02 respectively for both and these values were statistically significant $(p<0.001)$. On the other 
hand there wasn't any correlation between the spirometric parameters and diffusion capacity as well as with the muscle strength.

There was cleft lip and palate in the babies of three women at dyspnea group. APGAR scores of all the babies in both groups were 2 . The mean weight gain of the women in the group without dyspnea was $13.38 \pm 4.55 \mathrm{~kg}$ and the mean birth weight of the babies was $3059.23 \pm 462.33 \mathrm{~g}$ in this group whereas these values were $14.00 \pm 3.95 \mathrm{~kg}$ and $3016.92 \pm 537.93 \mathrm{~g}$ respectively. In the group without dyspnea, out of 26 deliveries 12 was vaginal and 14 was cesarean section. On the other hand in the dyspnea group there was 6 vaginal delivery out of 26 (Table 3 ).

Table I The spirometric parameters, diffusion and muscle strength values of pregnants according to their trimesters

\begin{tabular}{|c|c|c|c|c|}
\hline & Trimester & Trimester & Trimester & $\mathbf{P}$ \\
\hline $\mathrm{FVC}(\mathrm{ml})$ & $3475.00 \pm 564.82$ & $3392,3 I \pm 589.06$ & $3458.08 \pm 368.52$ & $p>0.05$ \\
\hline FVC $\%$ & $104.46 \pm 13.04$ & $101.92 \pm 11.81$ & $102.12 \pm 8.22$ & $p>0.05$ \\
\hline $\mathrm{FEV}_{1}(\mathrm{ml})$ & $2902.31 \pm 433.35$ & $2896.54 \pm 556.57$ & $2861.15 \pm 300.15$ & $p>0.05$ \\
\hline $\mathrm{FEV}, \%$ & $100.27 \pm 10.72$ & $99.73 \pm 12.14$ & $97.27 \pm 8.48$ & $p>0.05$ \\
\hline $\mathrm{FEV}_{\mathrm{I}} / \mathrm{FVC}$ & $83.65 \pm 4.89$ & $85.27 \pm 5.03$ & $82.88 \pm 3.98$ & $p>0.05$ \\
\hline $\mathrm{FEF}_{25-75}(\mathrm{ml})$ & $3064.23 \pm 625.49$ & $3319.62 \pm 905.05$ & $3041.04 \pm 596.99$ & $p>0.05$ \\
\hline $\mathrm{FEF}_{25-75} \%$ & $77.54 \pm 14.36$ & $85.04 \pm 21.05$ & $77.54 \pm 16.02$ & $p>0.05$ \\
\hline $\mathrm{DLCO} \mathrm{ml} / \mathrm{mmHg} / \mathrm{min}$ & $22.85 \pm 3.62$ & $22.14 \pm 4.07$ & $22.55 \pm 3.90$ & $p>0.05$ \\
\hline DLCO\% & $87.92 \pm 12.20$ & $85.23 \pm 14.69$ & $85.77 \pm 16.85$ & $p>0.05$ \\
\hline $\mathrm{DLCO} / \mathrm{VA} \mathrm{ml} / \mathrm{mmHg} / \mathrm{min} / \mathrm{ml}$ & $5.27 \pm 0.67$ & $5.26 \pm 0.81$ & $5.29 \pm 1.12$ & $p>0.05$ \\
\hline DLCO/VA\% & $92.00 \pm 10.39$ & $91.65 \pm|2.5|$ & $93.42 \pm 18.75$ & $p>0.05$ \\
\hline $\mathrm{RV}(\mathrm{ml})$ & $126|| 5 \pm 293.22$. & I I95.38 253.98 & $1203.46 \pm 233.75$ & $p>0.05$ \\
\hline RV\% & $97.88 \pm|9.5|$ & $93.77 \pm 17.36$ & $91.19 \pm 13.00$ & $p>0.05$ \\
\hline $\mathrm{TLC}(\mathrm{ml})$ & $4516.92 \pm 756.08$ & $4374.62 \pm 710.53$ & $4472.31 \pm 498.32$ & $p>0.05$ \\
\hline TLC\% & $99.08 \pm 13.35$ & $96.27 \pm 10.92$ & $96.12 \pm 7.66$ & $p>0.05$ \\
\hline $\operatorname{Pemax}(\mathrm{ml})$ & $104.49 \pm 23.38$ & $103.19 \pm 22.61$ & $98.74 \pm 16.52$ & $p>0.05$ \\
\hline Pemax\% & $70.62 \pm 16.13$ & $68.12 \pm 14.08$ & $66.27 \pm 13.70$ & $p>0.05$ \\
\hline $\operatorname{Pimax}(m l)$ & $78.34 \pm 20.91$ & $78.65 \pm 19.88$ & $71.18 \pm 18.09$ & $p>0.05$ \\
\hline Pimax\% & $90.65 \pm 25.14$ & $89.50 \pm 23.15$ & $81.50 \pm 22.43$ & $p>0.05$ \\
\hline
\end{tabular}

Table 2 The pulmonary functional parameters of the pregnant women with and without dyspnea in last trimester

\begin{tabular}{|c|c|c|c|}
\hline & $\begin{array}{l}\text { Without dyspnea } \\
N=26\end{array}$ & $\begin{array}{l}\text { With dyspnea } \\
N=26\end{array}$ & $\mathbf{p}$ \\
\hline $\mathrm{FVC}(\mathrm{ml})$ & $3503.85 \pm 402.69$ & $34|2.3| \pm 340.93$ & $p>0.05$ \\
\hline FVC\% & $104.38 \pm 7.75$ & $99.85 \pm 8.34$ & $p>0.05$ \\
\hline $\mathrm{FEV}_{1}(\mathrm{ml})$ & $2978.46 \pm 284.68$ & $2743.85 \pm 277.17$ & $\mathrm{p}=0.045$ \\
\hline $\mathrm{FEV}, \%$ & $102.08 \pm 6.48$ & $92.46 \pm 7.60$ & $\mathrm{P}=0.002$ \\
\hline $\mathrm{FEV}_{1} / \mathrm{FVC}$ & $85.38 \pm 2.56$ & $80.38 \pm 3.59$ & $\mathrm{p}=0.001$ \\
\hline $\mathrm{FEF}_{25-75}(\mathrm{ml})$ & $3455.15 \pm 367.23$ & $2626.92 \pm 485.87$ & $\mathrm{p}=0.001$ \\
\hline $\mathrm{FEF}_{25-75} \%$ & $88.62 \pm \mid 1.71$ & $66.46 \pm 11.48$ & $\mathrm{p}=0.001$ \\
\hline $\mathrm{DLCO} \mathrm{ml} / \mathrm{mmHg} / \mathrm{min}$ & $23.57 \pm 4.26$ & $21.53 \pm 3.36$ & $p>0.05$ \\
\hline DLCO\% & $90.46 \pm 19.22$ & $81.08 \pm 11.33$ & $p>0.05$ \\
\hline $\mathrm{DLCO} / \mathrm{VA} \mathrm{ml} / \mathrm{mmHg} / \mathrm{min} / \mathrm{ml}$ & $5.5 \mid \pm 1.23$ & $5.07 \pm 0.99$ & $p>0.05$ \\
\hline DLCO/VA\% & $97.31 \pm 20.62$ & $89.54 \pm 16.48$ & $p>0.05$ \\
\hline $\mathrm{RV}(\mathrm{ml})$ & $|205.38 \pm 282.2|$ & $|20| .54 \pm \mid 84.88$ & $p>0.05$ \\
\hline $\mathrm{RV} \%$ & $91.08 \pm 14.08$ & $91.31 \pm 12.40$ & $p>0.05$ \\
\hline $\mathrm{TLC}(\mathrm{ml})$ & $4497.69 \pm 552.11$ & $4446.92 \pm 459.46$ & $p>0.05$ \\
\hline TLC\% & $96.92 \pm 7.07$ & $95.31 \pm 12.40$ & $p>0.05$ \\
\hline Pemax (ml) & $99.21 \pm 17.58$ & $98.27 \pm 16.10$ & $p>0.05$ \\
\hline Pemax\% & $65.69 \pm 12.50$ & $66.85 \pm 15.30$ & $p>0.05$ \\
\hline $\operatorname{Pimax}(\mathrm{ml})$ & $68.02 \pm 22.71$ & $74.34 \pm \mid 2.01$ & $p>0.05$ \\
\hline Pimax\% & $77.54 \pm 27.30$ & $85.46 \pm 16.39$ & $p>0.05$ \\
\hline
\end{tabular}


Table 3 Perinatal outcomes

\begin{tabular}{|c|c|c|c|}
\hline & & $\begin{array}{l}\text { Without dyspnea group } \\
N=26\end{array}$ & $\begin{array}{l}\text { With dyspnea group } \\
N=26\end{array}$ \\
\hline & Vaginal & 12 & 6 \\
\hline Type of Delivery & Ceserean Section & 14 & 20 \\
\hline \multicolumn{2}{|c|}{ Birth Weight of the Baby $(\mathrm{g})$} & $3059.23 \pm 462.33$ & $3016.92 \pm 537.93$ \\
\hline \multicolumn{2}{|c|}{ Total Weight Gain During Pregnancy (kg) } & $13.38 \pm 4.55$ & $14.00 \pm 3.95$ \\
\hline \multicolumn{2}{|c|}{ Presence of Anomaly } & I & 2 \\
\hline \multicolumn{2}{|c|}{ APGAR Score of the Baby } & 2 & 2 \\
\hline
\end{tabular}

\section{Discussion}

Significant adaptation physiological changes occur in respiratory systems during pregnancy. ${ }^{1,3}$ Different outcomes have been reported in different studies. McCormick and Wise ${ }^{3}$ reported that the movement and contractility of the diaphragm decreases and the diaphragm is pushed upward through the thorax during pregnancy. ${ }^{15}$ In the studies of Gazioglu and Gee increase in VC and IC, decrease in ERV and $\mathrm{RV}$ were reported which correspondingly resulted with a decrease in FRC. ${ }^{2,11}$ Our results were correlated with older studies as well. The decrease in static lung volumes was found to be associated with the decrease in the compliance of the chest wall and mechanical factors. ${ }^{3,8}$ The dynamic airway parameters such as $\mathrm{FEV}_{1}$ and $\mathrm{FEV}_{1} / \mathrm{FVC}$ may show minimal and insignificant changes but pregnancy is not found to be responsible from these changes. ${ }^{15,16}$ In their study Dipok and Nuamii et al. detected a decrease in $\mathrm{FEV}_{1}$ and $\mathrm{FEV}_{1} / \mathrm{FVC}$ values as the pregnancy progressed. ${ }^{4,5} \mathrm{We}$ also detected a decrease in our study in $\mathrm{FVC}, \mathrm{FEV}_{1}, \mathrm{FEV}_{1} / \mathrm{FVC}, \mathrm{FEF}_{25-75}, \mathrm{RV}$ and TLC values but the decrease was not statistically significant generally. Our result is consistent with the results of Dipok and Nuamii et al.'s study. Despite the mechanical effects of the progressively growing uterus; the insignificant decrease in $\mathrm{FVC}, \mathrm{FEV}_{1}, \mathrm{FEV}_{1} / \mathrm{FVC}$ suggests that some other factors such as nutrition, socioeconomically condition and hormonal changes may be contributing.

Diffusion capacity is defined as the volume of a gas $(1 / \mathrm{mL})$ diffused through the alveolocapillary membrane under a certain pressure gradient $(1 \mathrm{mmHg})$ in a certain period of time (1 minute). The standard gas used in diffusion assays is carbon monoxide. The diffusion capacity might be affected by a variety of factors including age, height, body surface area, smoking, hemoglobin levels, body posture and exercise, expiration and inspiration phases, high altitude, oxygen concentration, diurnal changes, menstruation, alcohol consumption, gender and ethnicity. Obstructive lung diseases, parenchymal diseases, systemic diseases affecting lungs and cardiopulmonary diseases are all known to decrease DLCO level..$^{1,10,17}$ Cardiac flow and blood volume increases during pregnancy. ${ }^{12}$ This becomes in equilibrium with the dilutional decrease in heamoglobin concentration. As a result DLCO stays steady or decreases minimally. ${ }^{1}$ Wilson has reported that DLCO was high in the first trimester yet gradually decreased. While Krumholz et al., ${ }^{18}$ didn't detect any change in diffusion capacity Gazioglu and Milne detected a decrease in the last trimester. ${ }^{10,11,18}$ We detected a decrease as well in the diffusion capacity in the last trimester which is consistent with the results of Gazioglu et al., ${ }^{11}$

PEmax and PImax are measurements of oral pressure at maximal respiratory state against a valve obstructing the airway at maximum inspiration and expiration. Data about PImax and PEmax during pregnancy are not enough. Respiratory pump is associated with the effective and coordinated function of the respiratory muscles, the airway resistance, elastic force of the lung and also with the normal structure of the parietal tissues. To evaluate the inspiratory and expiratory muscle strength during pregnancy, transdiaphragmatic pressure measurement, the pressure and volume changes of the rectus abdominis muscle were examined in some studies but they concluded that PImax and PEmax measurement was a more simple and noninvasive method. ${ }^{8,9,19,20}$ Lemos and Contreas detected that the muscle strength was unchanged and it wasn't associated with either BMI or weight. ${ }^{8,9}$ We used noninvasive PImax and PEmax measurements in our study to evaluate the muscle strength and we detected that muscle strength decreased during the course of pregnancy but it was not statistically significant.

Dyspnea is a frequent sypmtom during pregnancy.,3,4,5,9,16,21 It is common durig rest and on mild exercise. It begins at the first or second trimester. Increased respiratory stimulus and respiratory load, increased pulmonary blood flow, anemia and nasal congestion were considered to have a place in the etiology. ${ }^{3,21}$ In one of the studies it was found out that there was no association between PImax PEmax but in PImax linear regression models a negative correlation was detected between exertional dyspnea and height parameters. It was suggested that the increase at respiratory drive was because of a mechanical setting failure and an improper increase in IC. ${ }^{20,21}$ During pregnancy VT increases and this increase causes a decrease in total thoracic compliance which accordingly causes a mechanical restriction in muscles and consequently a further increase at dyspnea during pregnancy without any disorder in intraabdominal compartments. Progesterone may also be held responsible for dyspnea since it increases the respiratory stimulus. ${ }^{8,20,21}$ In our study dyspnea score was significantly high in parallel with the uterine fundus height in the last trimester.

\section{Conclusion}

In summary there wasn't any significant change in spirometric parameters, diffusion capacity and muscle strength during pregnancy. This gives the impression that mechanical restriction is the primary effect in the development of dyspnea. The caesarean section ratio was significantly high in the group with dyspnea. We concluded that close follow up of respiratory functions may be mandatory in pregnancy because of its effects on type of delivery.

\section{Acknowledgements}

None.

\section{Conflict of interest}

The author declares no conflict of interest. 


\section{References}

1. Hegewald MJ, Crapo RO. Respiratory physiology in pregnancy. Clin Chest Med. 2011;32(1):1-13.

2. Gee JB, Packer BS, Millen JE, et al. Pulmonary mechanics during pregnancy. J Clin Invest. 1967;46(6):945-952.

3. McCormack MC, Wise RA. Normal Pregnancy. In: Bourjeily G, et al editors. Pulmonary Problems in Pregnancy, Respiratory Physiology in Pregnancy. USA: Humana Press a part of Springer Science-Business Media. 2009. p. 19-26.

4. Dipok KS, Ruhul A, Ayesha Y, et al. Study of forced expiratory volume in first second $\left(\mathrm{FEV}_{1}\right)$ and ratio of forced expiratory volume in first second and forced vital capacity in percentage $\left(\mathrm{FEV}_{1} / \mathrm{FVC} \%\right)$ in pregnant women. J Enam Med Col. 2012;2(1):29-32.

5. Salman HN, Adnan MJ, Kasim MS, et al. Physiological changes in spirometric parameters during pregnancy In Iraqi women. J Fac Med Baghdad. 2012;54(4):321-324.

6. Gilroy RJ, Mangura BT, Lavietes MH. Rib Cage and abdominal volume displacements during breathing in pregnancy. Am Rev Respir Dis. 1988;137(3):668-672.

7. Prowse CM, Gaensler EA. Respiratory and acid-base changes during pregnancy. Anesthesiology. 1965;26:381-392.

8. Contreras G, Gutierrez M, Beroiza T, et al. Ventilatory drive and respiratory muscle function in pregnancy. Am Rev Respir Dis. 1991;144(4):837841 .

9. Lemos A, de Souza AI, Figueiroa JN, et al. Respiratory muscle strength in pregnancy. Respir Med. 2010;104(11):1638-1644.

10. Milne JA, Mills RJ, Coutts JR, et al. The effect of human pregnancy on the pulmonary transfer factor for carbon monoxide as measured by the single breath method. Clin Sci Mol Med. 1977;53(3):271-276.
11. Gazioglu K, Kaltreider NL, Rosen M, et al. Pulmonary function during pregnancy in normal women and in patients with cardiopulmonary disease. Thorax. 1970;25(4):445-50.

12. Pritchard JA. Changes in the blood volume during pregnancy and deliverey. Anesthesiology. 1965;26:393-399.

13. Borg G. Borg's perceived exertion and pain scales. Illinois, USA: Human Kinetics Publishers; 1998. 104 p.

14. American Thoracic Society/European Respiratory Society. Statement on respiratory muscle testing. Am J Respir Crit Care Med. 2002;166(4):518624.

15. Harik-Khan R, Wise RA, Lou C, et al. The effect of gestational parity on $\mathrm{FEV}_{1}$ in a group of healty volunteer women. Respir Med. 1999;93(6):382-388.

16. Sroczynski T. Evaluation of respiratory tract function in healthy women in the last month of uncomplicated pregnancy. Ann Acad Med Stetin. 2002;48:331-350.

17. Wilson AF. Pulmonary physiology and pulmonary diseases in pregnancy. Principles of Medical Therapy in Pregnancy. 1985. p. 739-747.

18. Krumholz RA, Echt CR, Ross JC. diffusing capacity, capillary blood volume, lung volumes, and mechanics of ventilation in early and late pregnancy. J Lab Clin Med. 9164;63:648-55.

19. Windisch W, Hennings E, Sorichter S, et al. Peak or plateau maximal inspiratory inspiratory mouth pressure: Which is best? Eur Respir J. 2004;23(5):708-713.

20. Gaensler EA, Patton WE, Verstraeten JM, et al. Pulmonary function in pregnancy. Am Rev Tuberc. 1953;67:779.

21. Milne JA. The respiratory response to pregnancy. Postgrad Med J. $1979 ; 55(643): 318-324$. 